\title{
Visual Outcome of Manual Small Incision Cataract Surgery and Phacoemulsification in a Tertiary Care Center
}

\author{
Hina Kounsar ${ }^{1}$, Suhail Raheem Rather ${ }^{2}$, Sheikh Sajjad ${ }^{3}$, Uroosa Farooq ${ }^{4}$ \\ ${ }^{1}$ Department of Ophthalmology, SKIMS-MCH, Srinagar, India. \\ ${ }^{2}$ Medical Officer, Department of Health and Medical Education, Srinagar, India. \\ ${ }^{3}$ Department of Ophthalmology, SKIMS-MCH, Srinagar, India. \\ ${ }^{4}$ Department of Community Medicine, SKIMS-MCH, Srinagar, India. \\ Corresponding Author: Hina Kounsar
}

DOI: https://doi.org/10.52403/ijrr.20220201

\begin{abstract}
Introduction: Phacoemulsification is considered the gold-standard procedure for cataract. However, MSICS being less expensive can be considered a better procedure for doing mass surgeries. The purpose of this comparative hospital-based study was to assess the visual outcome in the post-operative patients of MSICS and Phacoemulsification.

Method: 160 consecutive patients who completed the post operative follow up of 6 weeks were included in our study with two groups of 80 patients each. One group of patients were operated by MSICS and another by Phacoemulsification. Proper ocular examination including visual acuity (aided and unaided), pupillary reaction, slit lamp examination and fundus was evaluated at week 1 and week 6.

Results: Amongst the 80 cases of phacoemulsification $74(92.5 \%)$ had unaided visual acuity of $6 / 18$ or better at week 1 . In case of MSICS unaided visual acuity of $6 / 18$ or better was present in only $62(77.5 \%)$ cases at week 1 . The results were statistically significant ( $\mathrm{P}<0.01)$ in favour of Phacoemulsification. At week 6 Visual Acuity of $6 / 18$ or better was present in $76(95 \%)$ and 67 (83.5\%) patients in Phacoemulsification and MSICS methods respectively, though better in phacoemulsification group it was not statistically significant $(\mathrm{P}>0.01)$. Similar was case with Best Corrected Visual Acuity at week 6.
\end{abstract}

Conclusion: Phacoemulsification gives better UCVA at $1^{\text {st }}$ week than MSICS though both are equally safe and efficacious procedures with low complication rates and same visual outcome when compared at 6 weeks. MSICS can thus be an alternative wherever the requisite equipment and expertise for PHACO are not available.

Key Words: Manual Small Incision Cataract Surgery, Phacoemulsification, Visual outcome, surgical induced astigmatism.

\section{INTRODUCTION}

Senile cataract is an age related, vision impairing disease characterized by gradual and progressive thickening of the lens. Cataract is one of the leading causes of treatable blindness in the world [1]. Modern cataract surgeries with the intraocular lenses are the safest, successful, and most frequently performed surgeries [2-6]. The main objective of these surgeries is to obtain early visual rehabilitation and a better unaided visual acquity with minimal surgical complications [7-8]. Our study included two main techniques of cataract extraction mostly done nowadays that is Manual Small Incision Cataract Surgery (MSICS) and Phacoemulsification (Phaco). The evolution of surgical techniques has been mainly due to decrease in the size of incision. 
Phacoemulsification is considered the gold-standard procedure for cataract. However, MSICS being less expensive can be considered a better procedure for doing mass surgeries. Surgically induced astigmatism (SIA), which is common with MSICS, causes poor postoperative visual recovery in MSICS.

The purpose of this comparative hospital based study was to assess the visual outcome in the post-operative patients of MSICS and Phacoemulsification.

\section{MATERIAL AND METHODS}

A Prospective comparative hospital based study was conducted in the department of ophthalmology in SKIMS$\mathrm{MCH}$ BEMINA on patients undergoing cataract surgery by MSICS and Phacoemulsification.

160 consecutive patients who completed the post operative follow up of 6 weeks were included in our study with two groups of 80 patients each. One group of patients were operated by MSICS and another by Phacoemulsification. All the patients were above the age of 45 years in both the groups with visually significant age related uncomplicated cataract.

\section{Inclusion criteria:}

I. Patients whose age is greater or equal to 45 years,

II. Patients with Senile cataract.

III. Good intact zonular apparatus.

IV. Patients who are willing to participate in the study.

\section{Exclusion criteria:}

I. Any other type of cataract except senile cataract.

II. Patients with any ocular trauma or any intraocular surgery.

III. Patients with glaucoma, uveitis, pseudoexfoliation.

Demographic data of patients was collected including name, age, sex and occupation. Duration of diminution of vision was taken and other relevant past history including systemic diseases. Proper ocular examination including visual acuity (aided and unaided), pupillary reaction, and its dilating capacity was evaluated at week 1 and week 6. Slit lamp examination of anterior segment and fundus examination was carried out after pupillary dilatation to rule out other causes of diminution of vision.

Phacoemulsification was performed by experienced surgeons under Zeiss operating microscope. Chi-square test was used for finding level of statistical significance.

\section{RESULTS}

Of the 160 patients, who were included in the study, 73 were male and 87 female. The patients age ranged from 46-78 years, with a mean of 61.4 years.

8 cases of MSICS had Iris prolapse because of premature entry into the anterior chamber.6 patients of MSICS and 4 patients of phaco had corneal edema which subsided within a week or two. Table 1

Amongst the 80 cases of phacoemulsification $74 \quad(92.5 \%)$ had unaided visual acuity of $6 / 18$ or better at week 1 . In case of MSICS unaided visual acuity of $6 / 18$ or better was present in only $62(77.5 \%)$ cases at week 1 . The results were statistically significant $(\mathrm{P}<0.01)$ in favour of Phacoemulsification. Table 2

At week 6 Visual Acuity of $6 / 18$ or better was present in $76(95 \%)$ and 67 (83.5\%) patients in Phacoemulsification and MSICS methods respectively, though better in phacoemulsification group it was not statistically significant $(\mathrm{P}>0.01)$. Similar was case with Best Corrected Visual Acuity at week 6 where $78(97.5 \%)$ and $70(87.5 \%)$ cases in phacoemulsification and MSICS had Visual Acuity of $6 / 18$ or better respectively $(\mathrm{P}>0.01)$. Table 3

Table 1. Distribution of complication between two procedures.

\begin{tabular}{|l|l|l|}
\hline & MSICS & PHACO \\
\hline Corneal Oedema & 6 & 4 \\
\hline Striate Keratopathy & 8 & 1 \\
\hline Posterior Capsule Rent & 3 & 2 \\
\hline Iris prolapse & 8 & 0 \\
\hline Iridodialysis & 4 & 0 \\
\hline
\end{tabular}


Hina Kounsar et.al. Visual outcome of manual small incision cataract surgery and phacoemulsification in a tertiary care center.

Table 2. Visual Acuity at week 1 and week 6 in SICS and Phacoemulsification respectively.

\begin{tabular}{|c|c|c|c|c|c|c|}
\hline & \multicolumn{3}{|c|}{ VA at week 1} & \multicolumn{3}{|c|}{ VA at week 6} \\
\hline & MSICS & PHACO & P-valve & MSICS & PHACO & P-value \\
\hline $6 / 18$ or better & $62(77.5 \%)$ & $74(92.5 \%)$ & $\mathrm{X}^{2}=7.0588$ & $67(83.75 \%)$ & $76(95 \%)$ & $X^{2}=5.3311$ \\
\hline Worse than $6 / 18$ & $18(22.5 \%)$ & $6(7.5 \%)$ & $\begin{array}{l}\mathrm{P} \text { value }=0.0079 \\
(<0.01)\end{array}$ & $13(16.25 \%)$ & $4(5 \%)$ & $\begin{array}{l}P \text { value }=0.0209 \\
(>0.01)\end{array}$ \\
\hline Total & 80 & 80 & & 80 & 80 & \\
\hline
\end{tabular}

Table 3. Best corrected Visual Acuity at week 6 in SICS and Phacoemulsification respectively.

\begin{tabular}{|l|l|l|l|}
\hline & MSICS & PHACO & P-value \\
\hline $6 / 18$ or better & $\begin{array}{l}70 \\
(87.5 \%)\end{array}$ & $\begin{array}{l}78 \\
(97.5 \%)\end{array}$ & $\begin{array}{l}\mathrm{X}^{2}=5.7658 \\
\mathrm{P} \text { value }=0.0163 \\
(>0.01)\end{array}$ \\
\hline $\begin{array}{l}\text { Worse than } \\
6 / 18\end{array}$ & $\begin{array}{l}(12.5 \%) \\
(12.5 \%)\end{array}$ & $2(2.5 \%)$ & \\
\hline Total & 80 & 80 & \\
\hline
\end{tabular}

\section{DISCUSSION}

There was no significant age difference between the two groups and the mean age amongst the 160 cases in our study was 61.4 years. The age was comparable with results in other studies [9, $10,11]$.

In this study there was not much significant difference between the various groups in terms of distribution of gender which is constant with the results observed in the previous studies which showed no difference in terms of gender $[11,12]$.

There was a significant difference in visual outcomes between MSICS and Phacoemulsification surgical methods at 1 week, but significance decreased by 6 weeks. Similarly, Gamal Mostafa Abo El Maaty et al. [13] and Ruit S et al. [14] compared visual outcome of manual sutureless small incision cataract surgery (MSICS), planned extracapsular cataract extraction and phacoemulsification. These studies were in consistence with our study wherein there was a significant difference between various 2 groups in terms of distribution of Vision Category in first week. In a study by Rathi A et al [15] participants in the Group: Phacoemulsification had the better proportion of Vision Category (PostOperative Day-7) $6 / 18$ or better on 7 th postoperative day compared to MSICS group due the difference in the size of the incision and induced astigmatism.

Both the SICS and PHACO group of patients showed improvement in the vision from week 1 to week 6 , but at 6 weeks there was not much difference in outcome of PHACO and SICS group. Similar results were seen in number of studies. Wairagade $\mathrm{N}$ et al [16] in their study found that at 6 weeks post-operatively Phaco group $99.6 \%$ achieved BCVA $6 / 18$ or better as compared to $97.6 \%$ in SICS group. None of the patients had vision less than $6 / 60$ in their study and the difference in BCVA at 6 weeks between the phaco and SICS groups was not statistically significant $(\mathrm{p}=0.12)$. Similarly, Gogate PM et al [17] found out uncorrected visual acuity of $6 / 18$ or better in $81.1 \%$ patients in the phacoemulsification group and $71.1 \%$ patients in the SICS group at 6 weeks with no statistically significant difference in both the groups. The BCVA was also comparable in the two groups. Comparable visual outcomes after $4-6$ weeks between manual SICS and phacoemulsification were also seen in number of other studies like Ruit et al [14], Venkatesh et al., [4]. Singh S.K.et al [12]. Husain $R$ et al [18] found very little difference between manual SICS and Phacoemulsification in terms of visual outcome at $4-11$ weeks visit $(89.50 \%$ vs $88.20 \%$ ).

Cook et al [19] in their study reported incidence of $0.1 \%$ PCR in the SICS group and $0.04 \%$ in the phaco group. While there was a higher incidence of complications like posterior capsule rent, vitreous loss, in the eyes having manual small-incision surgeries, this difference was not statistically significant $(\mathrm{P}=0.34)$.

Iridodialysis occurred in 4 cases of SICS (1.6\%) and none was seen in the phaco group. All cases were related to difficulty while delivering the nucleus. The higher incidence was probably because of the larger size of the incision in SICS, but the difference was not statistically significant. Gogate et al [17] and Singh et al [12] carried out a comparative study of 
iridodialysis in two groups and found out that incidence is comparable. Haripriya A.et al [20] suggests that Iridodialysis though rare with both procedures, occurred statistically more often with MSICS than in phaco groups.

\section{CONCLUSION}

From our study we conclude that though PHACO is better than SICS due to its small incision which heals rapidly and gives early visual rehabilitation at $1^{\text {st }}$ week post operatively but both are equally safe and efficacious procedures with low complication rates and same visual outcome when compared at 6 weeks. MSICS can thus be an alternative wherever the requisite equipment and expertise for PHACO are not available.

\section{Acknowledgement: None}

\section{Conflict of Interest: None}

\section{Source of Funding: None}

\section{Ethical Approval: Approved}

\section{REFERENCES}

1. Yorston D, Gichuhi S, Wood M, Foster A. Does prospective monitoring improve cataract surgery outcomes in Africa? Br J Ophthalmol. 2002 May;86(5):543-7.

2. Gonglore B, Smith R. Extra-capsular cataract extraction to phaco-emulsification: why and how? Eye 1998; 12:976-982.

3. El-Sayed SH, El-Sobky HM, Badawy NM, El-Shafy EA. Phacoemulsification versus manual small incision cataract surgery for treatment of cataract. Menoufia Med J 2015; 28:191-196.

4. Venkatesh, R., Das, M., Prashanth, S., \& Muralikrishnan, R. (2005). Manual small incision cataract surgery in eyes with white cataracts. Indian journal of ophthalmology, 53(3), 173.

5. McCarey, B. E., Polack, F. M., \& Marshall, W. (1976). The phacoemulsification procedure. The effect of intraocular irrigating solutions on the corneal endothelium. Investigative Ophthalmology \& Visual Science, 15(6), 449-457.
6. Tabin G, Chen M, Espandar L. Cataract surgery for the developing world. CurrOpin Ophthalmol. 2008 Jan;19(1):55-9

7. Ravindran RD, Haripriya A, Minu M. In: Ashok G, Luther L, Geoffery T, et al. editors. Relevance and clinical significance of SICS (manual phaco) in modern cataract surgery. Clinical practice in small incision cataract surgery (phaco manual). 1st ed. Jaypee Brothers; 2005. 238-240.

8. MitchellPW. Update on bimanual microincisional cataract surgery. Curr Opin Opthalmol 2006; 17:62-67

9. Bandhu, S. D., Vabale, Y. G., Sambarey, P. P., Walke, A. B., \& Raje, S. (2016). Impact of cataract on the quality of life of rural patients in India. Journal of Clinical Ophthalmology and Research, 4(2), 75.

10. Domple, V. K., Gaikwad, A. V., Khadilkar, H. A., Doibale, M. K., \& Kulkarni, A. P. (2011). A study on visual outcomes after cataract surgery with intraocular lens implants at the rural health training center, Paithan, Maharashtra. Indian journal of public health, 55(1), 22.

11. Javed, U., McVeigh, K., Scott, N. W., \& Azuara Blanco, A. (2015). Cataract extraction and patient vision-related quality of life: a cohort study. Eye, 29(7), 921-925.

12. Singh SK, Winter I, Surin L. Phacoemulsification versus small incision cataract surgery (SICS): Which one is a better surgical option for immature cataract in developing countries? Nepal J Ophthalmol 2009;1:95-100.

13. El Maaty, G. M. A., Elmoddather, M., Elkareem, A. M. G., \& Shamselden, H. (2014). A Comparative Study Between Manual Small Incision Cataract Surgery, Planned Extracapsular Cataract Extraction and Phacoemulsification In Mature Cataract Cases. Journal of American Science, 10(10).

14. Ruit, S., Tabin, G., Chang, D., Bajracharya, et al. (2007). A prospective randomized clinical trial of phacoemulsification vs manual sutureless small incision extracapsular cataract surgery in Nepal. American journal of ophthalmology, 143(1), 32-38.

15. Rathi A, Singh N, Chauhan R.S. et al. (2020). "A Comparative Study to Evaluate Visual Outcome in Post-Operative Patients of Manual Small Incision Cataract Surgery 
Hina Kounsar et.al. Visual outcome of manual small incision cataract surgery and phacoemulsification in a tertiary care center.

and Phacoemulsification". Saudi J Med Pharm Sci, April., 2020; 6(4): 353-358.

16. Wairagade N, Deshmukh M , Pande C, et al. (2020). Comparison of Intraoperative and Postoperative Complications of Phacoemulsification and Small Incision Cataract Surgery in Central India. International Journal of Science and Healthcare Research, Jan.-March 2020; Vol.5; Issue: 1;

17. Gogate P, Deshpande M, Nirmalan PK. Why do phacoemulsification? Manual small-incision cataract surgery is almost as effective, but less expensive. Ophthalmology. 2007 May;114(5):965-8.

18. Husain R, Mohammad S, Mezbah U, et al. To Compare the Visual Outcome, Safety and Efficacy of Phacoemulsification and Small-Incision Cataract Surgery (SICS) at CEITC, Bangladesh. Jr. Institute of Community Ophthalmology and Chittagong
Eye Infirmary \& Training Complex 2013 Sept ; 8(9).:21-25.

19. Cook C. Cataract surgery in low income countries-phaco or SICS. In Vancouver; 2011. Asian Journal of Ophthalmology. 2002; 4(1): 9-11

20. Haripriya A, Chang DF, Reena M, Shekhar M. Complication rates of phacoemulsification and manual small incision cataract surgery at Aravind Eye Hospital. J Cataract Refract Surg. 2012 Aug;38(8):1360-9.

How to cite this article: Hina Kounsar, Suhail Raheem Rather, Sheikh Sajjad et.al. Visual outcome of manual small incision cataract surgery and phacoemulsification in a tertiary care center. International Journal of Research and Review. 2022; 9(2): 1-5. DOI: https://doi. org/10.52403/ijrr.20220201 